\title{
The Status of Minority Languages Under the Conditions of Multilingualism (Based on the Example of the Language Situation in Belgium and Canada)
}

\author{
Mariya SELIVERSTOVA \\ Ph.D. (in Philological Science) \\ Associate Professor \\ Department of Theory and Practice of Translation \\ Institute of Social Sciences and International Relations \\ Sevastopol State University \\ Room G-601, 33, Universitetskaya str., Sevastopol, the Russian Federation \\ $+79788992560$ \\ Mariya_HappyM@mail.ru

\section{Yuliya MARCHENKO} \\ Senior Lecturer \\ Department of Theory and Practice of Translation \\ Institute of Social Sciences and International Relations \\ Sevastopol State University \\ 33, Universitetskaya str., Sevastopol, the Russian Federation \\ $+79787093539$ \\ ciel_84@mail.ru
}

\begin{abstract}
The purpose of the article is to consider the status of the minority languages in the territory of modern Belgium and Canada, as well as their impact on the language conflicts in these regions. The study of the linguistic situation of Belgium and Canada is of great practical importance allowing us to reveal the basics and nature of the language policy of the states as a whole, to evaluate the prospects of a particular policy with regard to the state languages in the countries where the linguistic situation is extremely stressful. According to the aim, the following tasks were solved: defying the notion 'linguistic situation', studying the historical dynamics of the interaction of the languages which are components of the linguistic situation, considering the issue of the status of the languages in the multiethnic society, defying the main features of bilingualism, analyzing the
\end{abstract}


specific features of the language policy of the state, determining the parameters of the linguistic situation in Belgium and Canada. The study considers the world and regional language formations represented in the territory of Belgium and Canada. The research considers the topical issues of the language policy and the activity of the institutions that deal with monitoring the observation of the citizens' language rights and the settlement of the interlingual conflict. The results of the study can be used in the teaching of sociolinguistics, linguocultural studies, linguistic geography, and in students' scientific research.

Keywords: language situation; language policy; bilingualism; minority languages; linguistic crisis; Belgium; Canada.

\section{Introduction}

In the aspect of world integration and globalization linguists are becoming increasingly interested in studying the nature of linguistic situations and interlanguage interference in various regions of the world (Petrenko, 1998). Studying the linguistic situation of a country is of great practical importance. It allows to reveal the nature and foundations of the language policy of the state. In the situation of multilingualism, the 'language problem' becomes especially acute; the influence of public institutions on the functioning, development and interaction of languages, as well as on the status of minority languages and endangered languages, is growing (Shvejcer, 1978). This issue is relevant both for the European continent and for the countries beyond its borders.

The object of this study is the language situation in Belgium and Canada.

The subject of the study is minority languages in the territory of modern Belgium and Canada.

At the present stage of research qualitative and quantitative studies applying a unified system of signs significant for sociolinguistic typology in order to characterize linguistic situations in different regions are particularly relevant. The group of quantitative features of the language situation consists of the following parameters: the number of component languages of the language situation, the degree of ethnic linguistic diversity of the language situation, the demographic weight and the communicative power of component languages (Milroy, Milroy, 1998). The group of qualitative features includes the degree of genetic affinity, the level of prestige of languages as well as their legal status. Belgium and Canada are vivid examples of multinational states whose history is marked by the confrontation of peoples living in the same territory in an effort to preserve their native language, culture and their identity. The preservation and dissemination of languages, the 
support of national minorities and the indigenous population, the settlement of interethnic language conflicts are the essence of the language policy of both countries.

\section{Methods}

The choice of methods and the formation of a set of techniques for this sociolinguistic study is determined by the purpose of the work. The implementation of the method of the analytical review of the literature implies the analysis of scientific literature on the issues under study presented in the domestic and foreign linguistic traditions. For a sociophonetic analysis of the language situation in Belgium and Canada the method of statistical data processing was used. The method of 'grounded theory' and the method of induction are used to summarize the results of the study.

\section{Results}

The state of Belgium and the confrontation between two ethnic groups, the Walloons and the Flemings, lasting for centuries in its territory is of considerable interest to sociolinguists. However, no attention was paid to the analysis of the speech behaviour of informants, members of various social groups in Belgium. The problems of cross-language interference taking into account the share and role of other languages in the language situation of Belgium, various social groups and areas of communication were studied quite fragmentarily. From the point of view of the relevance of the work, we can say that the consideration and analysis of the language contact and language conflict using the Flemish language in Belgium as an example is important for the sociolinguistic analysis of the language problems in this region.

About 5 million people speak Flemish, mainly north of the language border that divides Belgium and runs from east to west south of Brussels. The Flemish language is used in everyday life by residents of the department of Nord in France. Having a German origin and being first subjected to Gallo-Roman, and later French linguistic and cultural influence, the Flemings make up the population of Flanders. Flemish belongs to the West German group (Berkov, 2001). In the 16th century there was a separation of the territories of Belgium and the Netherlands. Then there were language changes. In the 17th and 18th centuries Flemish dialects were used in the field of oral communication. They were hardly influenced by the development of the Dutch language. The Flemish language acquired its former significance in 1815, after the reunification of Belgium and the Netherlands. In 1830, after the emergence of independent Belgium, the Flemings opposed their language being still considered a local dialect. The normative literary language was approved with great difficulty as many wealthy and educated Flemings spoke French. In 1883 a law was passed expanding the rights of the Flemings in the use of their native language in the field of education (Labov, 1971). According to this law, the use of the Dutch language was allowed in primary and 
secondary schools. However, the first university with teaching in Dutch was opened in Ghent only in 1930 (Gutsul, 2011).

In the 1960s, Flanders became an autonomous entity of the federation with its own budget, parliament and government. The main legislative acts were adopted that established the use of official languages in various fields. Dutch became the only official language in all the parts of Flanders in 1963. In the periphery of Brussels, as well as in the districts bordering with Wallonia, a strictly limited use of the French language is allowed in the primary education of Francophones and in the provision of administrative services to the French-speaking population. Since 1966 a special commission (VasteCommissievoorTaaltoezicht) monitors the implementation of language legislation. Members of the commission are appointed for a period of 4 years. The laws adopted in 1962-1963 regulate the use of the languages in the field of secondary and primary education, disclose the mechanisms for obtaining education in the mother tongue of minorities within the linguistic region (Gutsul, 2011).

The Belgian variant of the Dutch language is often distinguished into a special 'Flemish' language (Janssens, 2008). Since 1973 by the decision of the Flemish Council for Culture the official linguonym which is used in the text of the Constitution is Nederlands. To name the dialects in the western part of Belgium the linguonym 'Flemish' (Vlaams) is used. Regarding the norm of the language, the same norm of the literary Dutch language is studied in Belgian schools as in the Netherlands. The population of the Netherlands and Flanders believes that the literary language in both countries is the same, despite some differences (Ronald van de, 2008). The Belgian variant of Dutch is distinguished by its lexical composition, its distinctive pronunciation and spelling, which is mainly associated with the interference of the French language (one of the two official languages in Belgium) (Labov, 2006).

Modern Flanders is a region where the language situation is extremely tense. The Flemish language has sufficient communicative power which is supported by the Constitution and the policy of 'linguistic federalism'. Despite the fact that the inhabitants of the originally Flemish city of Brussels are officially considered bilinguals, in practice $85-90 \%$ of the population of the city is Frenchspeaking, which is the result of Walloon expansion. However, the Brussels-Hal-Vilvorde district, the second largest constituency, which is also considered bilingual and where the majority of the population speaks French, the rights of this population in all matters related to the use of the French language, for example, obtaining information, cultural centers, libraries, doing business in the administration of communes and so on are limited. The Flemish language is preferred, although in some settlements the Flemish population is no more than 10\% (Kozhemjakina, 2009). 
During immigration from third countries and natural growth the French-speaking population of Brussels moves to the territory of Flanders, mainly to Flemish Brabant, where Francophones actually prevail in a number of municipalities and already account for at least $15 \%$ of the population. The authorities suppress any mention of the nationality or the language in censuses. The conflict potential on linguistic and cultural grounds continues to accumulate between the two communities (Flemish and French) and in other border regions, in particular in the Flemish exclave of Voeren (LePer-Zubkova, 2006).

According to Belgian law, the use of languages in the official sphere within linguistic regions is regulated on the basis of the concept of 'linguistic federalism'. Over the centuries, the WalloonFlemish conflict has had a peaceful and democratic nature of the reform process and has never entered the 'hot' stage. The conflict persisted only at the level of mutual claims. French was used throughout the country. It was an important tool for career growth. The Flemish has lost its influence, despite the fact that about $60 \%$ of the population considered it native. The ongoing reforms were based on progressive ideas and democratic values. At the same time, in general, the sphere of unofficial interpersonal communication is not affected, where the constitutional right to freedom of choice of a language acts (Giles, Smith, 1979). However, the 'borderline' area between official and unofficial use of the language remains a constant source of conflict situations. So, for example, in several Flemish cities near Brussels it is forbidden to sell land and municipal real estate to persons who do not speak the Flemish language (Ormonbekov, 2004).

Thus, to the Franco-Flemish conflict in the conditions of a united Belgium, which began exclusively on the linguistic plane, over time economic, political and ethnic components were added. In a number of border municipalities in Flanders the so-called language police operate. The Flemish region has a significant number of immigrants, and there is an ever-growing Frenchspeaking minority. Most Flemish people traditionally speak good French, and speak English. Linguistic differences in the country, according to sociolinguists, reveal the centuries-old problem of trying two nations, representatives of two different cultures, Latin and German, to live together in a single political and economic formation (Fishman, 1965).

The study of the 'language situation' is of great interest to domestic and foreign linguists (Ferguson, Avrorin (1975), Schweitzer, Desheriev, Nikolsky, Mikhalchenko, Mechkovskaya (2000)). As a rule, the linguistic situation in the region, several administrative-territorial units in the aggregate, in the state as a whole is investigated. As in Belgium, the linguistic situation in a multinational state such as Canada is of sociolinguistic interest. 
In Canada, a multicomponent exoglossic language situation has developed with two official languages - English and French. In terms of demographic weight, the linguistic situation in Canada is not balanced. English prevails over almost the entire territory of the state: for example, in the coastal provinces of Newfoundland and Labrador, Prince Edward Island and Nova Scotia the number of Anglophones reaches $90 \%$ of the population, and in the rest of the provinces with the exception of Quebec, New Brunswick and the territory of Nunavut Anglophones account for 70\% of the total number of inhabitants. The three border provinces of Quebec, Ontario, and New Brunswick have the largest number of Francophones. Their total number reaches $96.8 \%$ of the total number of the French-speaking population of the country (Leclerc, 2016).

In addition to the two officially recognized official languages, the languages of the autochthonous population and the languages of immigrants also function in Canada. The languages of the autochthonous population are most widely represented in Nunavut (84.9\%), in the Northwest Territories (50.2\%) and Yukon (25.1\%). 3.7\% of the Canadian population is indigenous (data for 2006). Three indigenous populations are recognized by the Canadian Constitution: Native Americans (59.5\%), Métis (33.2\%), and Inuit (4.3\%). In total, there are more than 50 indigenous languages or 'First Nations Languages'. Among them, the Cree languages have the highest demographic power and stability (of the 77,970 registered speakers, 46,760 use it in everyday communication), Inuktitut (31,925 and 25,040, respectively) and Ojibwe (24,025 and 11,005) (Leclerc, 2016). Since the number of speakers in some cases is only a few dozen, the existence of most indigenous languages is threatened with extinction. The tradition of language transfer from older generations to the younger among some peoples was interrupted (Kozhemjakina, 2009). In addition, according to many researchers, among the younger generations of the indigenous population there is a high level of bilingualism, and in some cases, for example, in urban conditions, English or French are preferred to the native language (Kozhemjakina, 2009). Thus, we can note the growing tendency to linguistic assimilation of indigenous peoples, which is associated with a decrease in interest in the native language of the native speakers themselves, as well as the low prestige of the languages of the indigenous population in society. In Canada an increase in the number of immigrants contributes to the spread of other languages and dialects. The number of the so-called allophones has now reached more than 5 million people. The federal census has shown that Chinese is the first widely spoken mother tongue for residents of Canada, Italian is the second, German is the third, and Punjabi is the fourth (Leclerc, 2016).

In modern Canada, English and French have unequal communicative power. Thus, according to the 2011 census, $66 \%$ of the country's inhabitants use English in everyday communication, 17.5\% of the Canadian population speak two languages: French and English, 21\% of the country's inhabitants 
use French in everyday life. For 18,858,975 Canadians of 33,476,688English is the native language, and French is for 7,054,970 residents (Leclerc, 2016). The official status of the two official languages guarantees the population of Canada the right to receive services at federal administrative institutions and judicial authorities in any of the official languages. However, bilingual services are not provided in municipalities and private enterprises located in English-speaking provinces. Francophones, whose number in these provinces is less than $5 \%$, are forced to use English in administrative institutions. Consequently, the legally fixed equal status of English and French is actually valid if it is used by a sufficient number of linguistic minorities. The state languages are equally used in various spheres of life: on labels and packaging of products, on monetary units, on postage stamps, at airports, on the radio. However, it should be noted that the services provided by post offices, the police and the armed forces are carried out mainly in English (Université d'Ottawa, 2016).

An important component of Canada's language situation is bilingualism. French is in continuous contact with English, as a result of which a situation of bilingualism and diglossy of English and French has developed in the country (Schiffman, 1998). The number of residents who speak the two official languages is 5,795,575, with the highest rates found in the provinces of Quebec (40.8\%), the only officially bilingual province of New Brunswick (34.2\%), on Prince Edward Island (12,0\%) and in Ontario (11.7\%) (Leclerc, 2016). Among the features of bilingualism in Canada, it should be emphasized its one-sided orientation. Among the population throughout the country bilingualism can be traced primarily among Francophones, while a small percentage of bilingualism is observed in English-speaking provinces.

Concerning the issue of languages functioning in Canada, it should be noted that English and French are related languages, being representatives of the West German group of the German branch and the Romance group of the Italian branch of the Indo-European language family, respectively. The languages of the autochthonous population represented in Canada belong to the Iroquois, Naden, Algonkin, and Eskimo-Aleut families. Thus, the linguistic situation in Canada is made up of both related and unrelated languages, as well as a number of isolate languages.

The question of the prestige of the official languages of Canada is connected with the history of the long Anglo-French conflict and the formation of national identity. The period from the signing of The Treaty of Paris, which signified the accession of Canada by Great Britain, until the time Canada gained independence was marked by the continuous struggle of the French Canadians for freedom, preservation of the national culture and native language. The adoption of the Quebec Act, as well as the British North America Act, ensured the right of the French-speaking population to use their 
native language in the areas of public administration, economics and civil law relations, and also allowed the French language to take a more solid position in society.

Regarding the legal status of languages, it is distributed in the provinces and territories of the state as follows: Alberta, Manitoba, Saskatchewan - English with a bilingual legal system, British Columbia, Prince Edward Island, Newfoundland and Labrador, Nova Scotia - English, Ontario English with the recognition of bilingualism, Quebec - French with the recognition of bilingualism, Yukon and the Northwest Territories - English and French have equal status, New Brunswick legally bilingual province Nunavut - English and French are legally recognized, Inuktitut and Inuinnaktun are actually used (Université d'Ottawa, 2016).

At present, despite the officially equal status of the two languages in the state, English has a dominant position in society and poses a serious threat to the spread of the French language and the increase in the number of French-speaking population. In this regard, the Government is making significant efforts to resolve issues related to the status of French and English, as well as the language rights of citizens. The priority direction of the state's internal policy is the development and spread of bilingualism and the protection of the French language. This is evidenced by the presence of a significant number of institutions whose activities are associated with the settlement of the interlingual conflict. The Royal Commission on Bilingualism and Biculturalism was created in 1963-1970. The key outcome of the commission's work was the first Law on Official Languages, passed by parliament in 1969. French and English were assigned equal status as the official languages of federal authorities. In addition, the Law aims to ensure the equality of the two languages in Canadian society, as well as to develop and support Anglophone and Francophone communities in a minority situation. The Commissioner of Official Languages of Canada monitors the implementation of the above decisions, as well as the observance of language rights of citizens.

\section{Discussion}

The study presents an analysis of the relevant issues of the language policy, and an examination of the existing institutions whose activities are related to monitoring the observance of the linguistic rights of citizens and the settlement of interlingual conflict. The article provides statistical data that clearly demonstrate the current features of the language situation in Belgium and Canada.

The linguistic situation in Belgium and Canada is a set of sub-situations in certain regions and provinces, formed under the influence of historical, socio-demographic, cultural and political factors, which suggests the need for a more detailed study of local language situations in the upcoming studies of the authors. 
The practical value of the presented work lies in the possibility of using its results in theoretical French courses, special courses and seminars on the theory of communication, intercultural communication, in the development of lecture material and in reading special courses on sociolinguistics.

The linguistic situation in Belgium and Canada is a set of sub-situations in certain regions and provinces formed under the influence of historical, socio-demographic, cultural and political factors, which suggests the need for a more detailed study of the local language situations in the upcoming studies of the authors.

The practical value of the presented work lies in the possibility of using its results in theoretical courses of French, special courses and seminars on the theory of communication, intercultural communication, in developing lectures and in reading special courses on sociolinguistics.

\section{Conclusion}

Modern life is characterized by political and economic shifts, which, in turn, are reflected in the intensity of the language processes that occur in all languages of the world. Globalization and the development of the media update the study of communication, first of all, what happens between representatives of different nationalities. Intercultural communication occurs with varying degrees of success and effectiveness, and therefore the achievement of a complete mutual understanding of the communicants. In the process of intercultural communication, the interaction of two or more languages at different levels is inevitable. Language contacts are one of the many consequences of communication between representatives of different nationalities, as well as cultural, economic and military-political relations between peoples.

The geographical location, historical situation, as well as economic, political and ethnic factors provoked the aggravation of the linguistic contradictions in such multilingual countries as Belgium and Canada. The dominant status of official and major languages negatively affects minority and endangered languages. Nevertheless, the organization of a competent language policy is one of the most important tasks of the state; its successful implementation harmonizes the situation within the country and helps to strengthen national identity.

The perspectives of this study can be seen in view of the fact that it makes up a basis for further research in the theory of language contacts when it comes to the Belgian and Canadian variants of the French language, to verbal interaction of global English and French in Belgium and Canada and to establishing the results of the functioning of the French language in the context of intercultural communication. 


\section{References}

Avrorin, V.A. (1975). Problems of studying the functional side of the language (on the subject of sociolinguistics). Leningrad: Nauka. (in Russian)

Berkov, V.P. (2001). Modern Germanic languages: textbook. Moscow: OOO 'Izdatel'stvo AST'. (in Russian)

Fishman, J.A. (1965). The Relationship Between Micro-and Macro-Sociolinguistics in the Study of Who Speaks What Language to Whom and When. Linguistics, 2, 153-165.

Giles, H., Smith, P.M. (1979). Accommodation Theory: Optimal Levels of Convergence. Language and Social Psychology. Baltimore: University Park Press, 45-65.

Gutsul, E. (2011). Belgium - a prison of two peoples. Kiev: Gazetnyj kompleks 'Internet-media', 9, 1, 6. (in Russian).

Janssens, R. (2008). Language use in Brussels and the position of Dutch. Some recent findings. Ejournal for academic research on Brussels, 13. Retrieved from: https://journals.openedition.org/brussels/520 (Accessed on February 9, 2020).

Kozhemjakina, V.A. (2009). Indigenous Peoples of Canada: Ethnic and Cultural Issues. Linguistics and methods of teaching foreign languages, 1, 18-37. (in Russian)

Labov, W. (1971). Variation in Language. The Learning of Language. National Council of Teachers of English.

Labov, W. (2006). The Social Stratification of English in New York City. Oxford University Press.

Leclerc, J. (2016). Donnéesdémolinguistiques. Recensement 2011. Université Laval. Retrieved from: http://www.axl.cefan.ulaval.ca/amnord/cnddemo.htm (Accessed on November 3, 2019) (in Russian)

LePer-Zubkova, L.V. (2006). The language situation in the Netherlands and Belgium: language policy without politicians? The solution of national language issues in the modern world, 233-262. (in Russian)

Mechkovskaya, N.B. (2000). Social linguistics. Moscow: Aspekt-press. (in Russian)

Milroy, J., Milroy, L. (1998). Varieties and Variation. The Handbook of Sociolinguistics. Oxford: Blackwell Publishing, 47-64. 
Ormonbekov, Z. (2004). From the foreign experience of federalism. The Belgian model of federalism: features and prospects. Kazan Federalist, 1(9). Retrieved from: http://www.kazanfed.ru/publications/kazanfederalist/n9/10/ (Accessed on November 11, 2019). (in Russian)

Petrenko, A.D. (1998). The sociophonetic variation of modern German in Germany. Kyiv: Arial. (in Russian)

Ronald van de, K. (2008). Native English for Nederlanders. A personal, cultural and grammatical guide. 6-de druk. Amsterdam: Business Contact, 78-104.

Schiffman, H.F. (1998). Diglossia as a Sociolinguistic Situation. The Handbook of Sociolinguistics. Oxford: Blackwell Publishing, 205-216.

Shvejcer, A.D. (1978). An introduction to sociolinguistics. Moscow: Vysshayashkola. (in Russian)

Université d'Ottawa. (2016). Contexte juridique des langues officielles au Canada. Site del'aménagement linguistique au Canada (SALIC). Retrieved from: https://salic.uottawa.ca/?q=anglais_francais_juridique (Accessed on November 9, 2019). 